\title{
RESEARCH
}

Open Access

\section{Coupling GIS and remote sensing techniques for coastal zone disaster management: the case of Southern Mississippi}

Yaw A. Twumasi ${ }^{1 *}$, Edmund C. Merem ${ }^{1}$ and Tomas Ayala-Silva ${ }^{2}$

\begin{abstract}
Background: Since hurricane Katrina, developer and planners are looking at a tools and sustainable ways to minimize vulnerabilities in events of disasters especially along the coast. In this setting, remote sensing and Geographic information systems (GIS) have the capacity to provide valuable and timely information about coastal resources, and form an important basis for sustainable planning for land management and decision making. This paper focuses on the design of appropriate coastal databases in six counties in Southern Mississippi using remote sensing and GIS technology. The intent is to enable planners and policy-makers contribute to improved land administration and coastal resources management in order to enhance their competence in decision-making. In order to achieve these objectives, satellite image and digital elevation models (DEMs) data were downloaded from the United States Geological Survey (USGS) seamless data warehouse National Elevation Dataset (NED). From there, the DEM data was co-registered to the satellite image to facilitate draping of the image over the DEM to create terrain models.
\end{abstract}

Results: Result reveals greater part of the three counties along the coast lies less than 10 meters above mean sea level with exposure to coastal disaster vulnerability.

Conclusions: In the context of the objectives of the research anchored on the applications of GIS and remote sensing towards efficient land administration and coastal resource management in six coastal counties in an ecologically fragile area already dubbed the epicenter of coastal disasters. Considering the changes that took place in the six counties after Hurricane Katrina debacle, the findings in this study not only stand out, but they remain highly beneficial to decision makers made up of planners and policy makers in several ways. Just as the study injected elements of novelty by identifying digital elevation model information for the six counties in low lying areas, revealing the steeper areas in the north portion of the study stands out as a major finding and study contribution in a way beneficial to decision makers in the region. With that they are now better informed in sharing and cautioning and pinpointing to the public the hidden critical pathways to coastal vulnerability that were previously unknown to ordinary people.

Keywords: Remote Sensing, GIS, Coastal zone management, Disaster management

\footnotetext{
*Correspondence: yaw.a.twumasi@jsums.edu

'Department of Urban and Regional Planning, Jackson State University,

Jackson, MS 39211, USA

Full list of author information is available at the end of the article
} 


\section{Background}

Coastal areas around the globe have come under intense pressure due to multiple reasons. High population growth, urban development coupled with the construction of fish ponds has resulted in serious environmental problems. The consequences have been disastrous over the last several centuries: An estimated 30\% of coastal land area has been changed or destroyed and $70 \%$ of all beaches have been eroded away (Romine and Fletcher 2013; Gillis 2014). Additionally, seagrass habitats are important to many aquatic species; but they are undergoing rapid destruction all over the world and especially in Southeast Asia where $20-60 \%$ of such environments have already been lost (Nadaoka 2005). Worldwide, between 35 and $50 \%$ of all pristine mangrove forests have been lost to human activity such as irrigation and dams, overharvesting, clearing for agricultural land, infrastructure and settlement (Oswell 2015). In Ghana, a study done by Twumasi et al. (2006) revealed the degradation of an extensive part of coastal areas along Accra by human activities such as the dumping of refuse and sand, coupled with mining of seashore sand for building purposes. Elsewhere, it has been predicted by scientists that many people could be affected in the United States Southeast coastal zones mostly from storms, high and extreme temperatures and others (Tibbets 2007). As one of the most sensitive and vulnerable systems, coastal zones' areas of concern include sea level rise, land loss, the frequency of maritime storms, flooding and responses to sea level rise (Rubinoff et al. 2008; Woodruff et al. 2013).

Notwithstanding various efforts by most coastal nations to regulate what happens in their coastlines and related environments. Judging by recent experiences, however, these initiatives remain ineffective largely due to fragmentation of authority and ineffective legislations as well as lack of proper enforcement, even when Environmental Assessment procedures are employed (Frihy 2001; Shi et al. 2001; Snoussi and Aoul 2000; Yap 2000). What is needed is integrated coastal zone management, requiring the use of the most advanced means of securing information for management purposes. Perhaps, the integration of Geographic Information Systems (GIS) and remote sensing data can play an important role in minimizing the danger posed by the flooding and sea level rise. Remote sensing data represents a powerful tool to understand the coastal processes where the images allow a synoptic view of an area and provide relation between coastal environment and vegetation and multi-temporal information (Twumasi et al. 2003, 2006, 2011; Osei et al. 2006; Pan 2005). In addition to integrated database, GIS combines different data sets and simultaneously, it facilitates the spatial and temporal analysis and the relationship between various coastal environments, allowing a more comprehensive, accurate and easier interpretation of coastal environmental features (Pan 2005). In Monterey Bay National Marine Sanctuary, Stanbury and Starr (1999) used GIS to map land and marine resources to create a database that could be used to improve coastal zone management in Central California. As a follow up, Van Heuvel (1995) examined the use of DTMs by the Government of the Netherlands to analyse beach and dune areas using digital photogrammetry and laser scanning. Taking cue from that, Van Heuvel (1995) noted the capacity of digital GIS techniques to deal with multimedia applications using data from widely differing sources to facilitate coastal management. While some of these studies are fully grounded with merits on the challenges of coastal areas in other places, very little effort has been directed to the southern Mississippi coastal area; an epicentre of past coastal disasters.

However, considering the implications on coastal ecological health, problems germane to the area were analyzed by a mix-scale approach using Geographic Information Systems (GIS) (Merem et al. 2011, 2012a, b). In the process, GIS applications use under a mix approach had not only been identified as decision support tool in coastal zone management, but serves a vital purpose for policy makers in tracking the emerging liabilities from coastal hazards and the associated factors in Louisiana. This came in the face of growing impacts of changing agricultural land landscape and the threats of climate change (Merem 2013). In related studies on the vulnerability of coastal Mississippi and Louisiana to climate change, spatial analysis revealed the gradual dispersion of risk patterns and the pathways of tropical storms over a period and the looming dangers of sea level rise and damages inflicted onto fragile environments comprising of open spaces and barrier islands during Hurricane Katrina (Merem et al. 2012a; Merem 2012). This is further compounded by the exposure of South Mississippi's costal ecosystem to stressors induced by human activities. Seeing the benefits of coastal zone management analysis in that fashion, Merem et al. (2012b) used GIS to monitor the risks from various stressors such as toxic releases, carcinogenic toxins and hazardous air and stream pollutants triggered by industrial activities and urbanization in the counties of South Mississippi (Merem et al. 2011, 2012b). While in the context of the study area, these themes are essential as Mississippi searches for the right tools necessary in the containment of coastal hazards in vulnerable communities, this research will contribute to the literature by coupling GIS and Remote Sensing techniques for costal disaster management in the Southern Mississippi area for effective management. 


\section{Objectives}

The objective of this study is to demonstrate how GIS and remote sensing techniques can guide planners and policy makers towards an improved land administration and coastal resources management in order to minimize natural disasters.

\section{Methods}

\section{Study area}

The focus areas of this study are six counties along the coast of Southern Mississippi including three adjacent counties north of the coastal counties. These counties are Hancock, Harrison, Jackson, George, Stone and Pearl River (Fig. 1).

The study area is part of the five largest Metropolitan Statistical Areas (MSAs) in Mississippi (Fig. 2; Table 1; U.S. Census Bureau 2013). From the 2000 population census, Gulfport - Biloxi Metropolitan Statistical Area (MSA) and Pascagoula MSA had a combined population of 246,190 and 150,564 respectively (Table 1 ). The GulfportBiloxi-Pascagoula MSA was significantly impacted by
Hurricane Katrina in 2005. Prior to the hurricane, the area had experienced steady to moderate population growth. For example data shown in Table 1 indicates that the population of Gulfport-Biloxi MSA grew $18.43 \%$ between 1990 and 2000 or at the rate of $1.8 \%$ annually. In the subsequent years between 2000 and 2010 , the population in the area grew $1.07 \%$ or at the rate of $0.11 \%$ annually. This decline was partly due to the Hurricane Karina in 2005 which caused some of the population to move out of the area. Similar increases in population was experienced in Pascagoula MSA between 1990 and 2000 where the population in the area grew $14.14 \%$ or at the rate of $1.41 \%$ annually. The area posted a decline in the population growth between 2000 and 2010 from a growth rate of 14.14 to $7.76 \%$ or at the rate of $0.78 \%$ annually.

Being at the epicenter of coastal disasters, the study area also experiences substantial flooding, especially during hurricane seasons. In a region known for tropical storms, Mississippi experiences it once on average of every of 12 years. A case in point is the visible damages

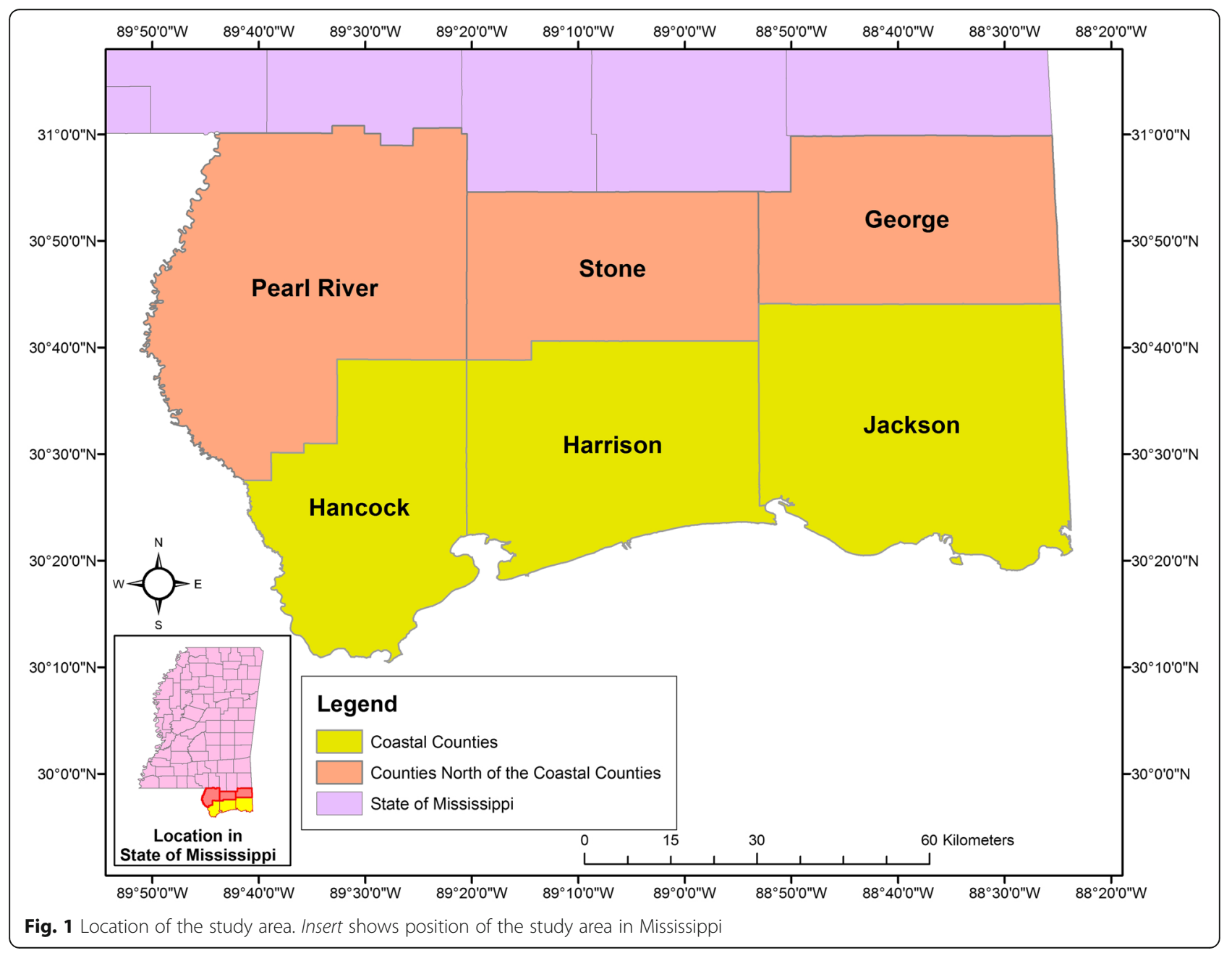




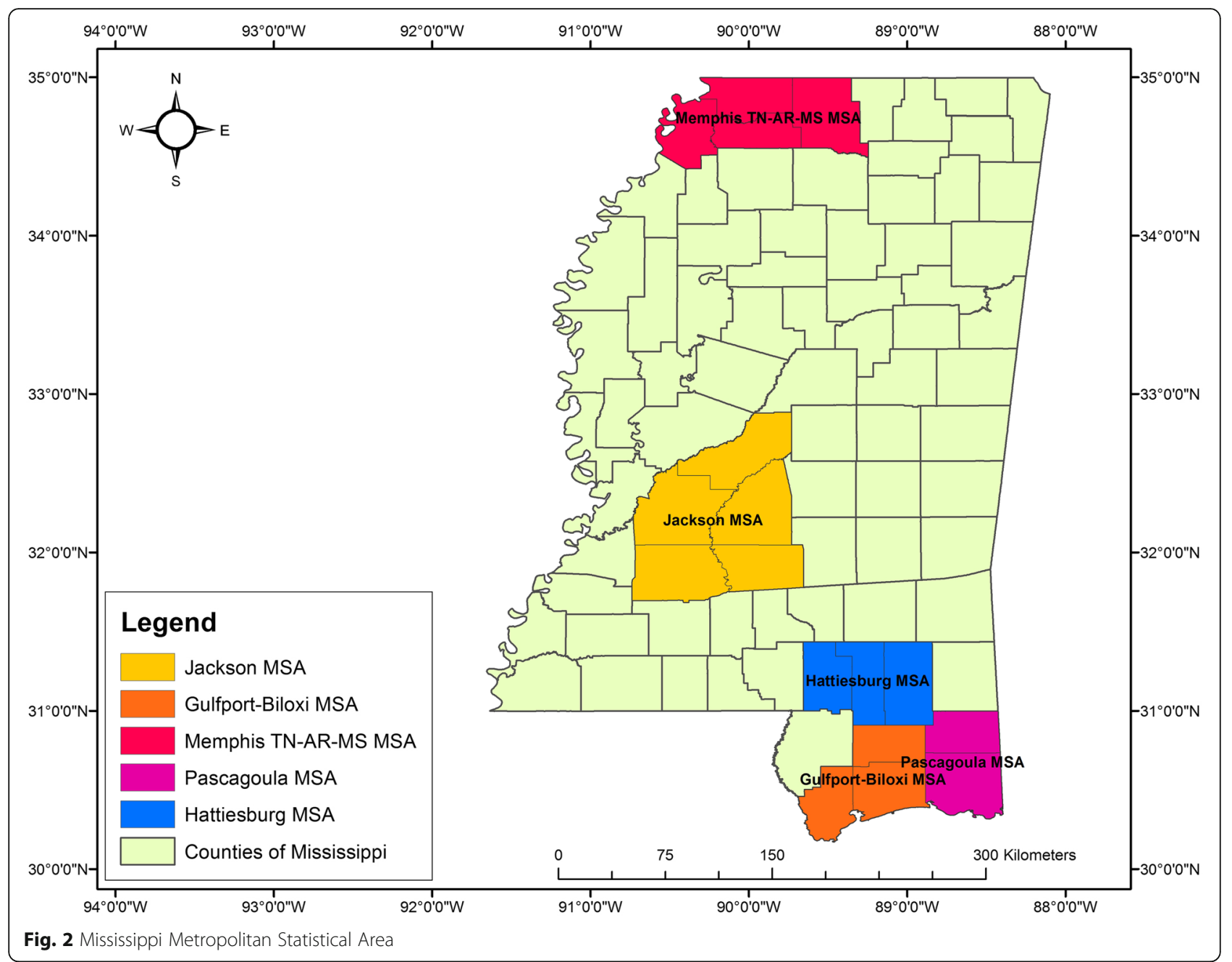

suffered by the states of Mississippi and Louisiana in 2005 August 25 when Hurricane Katrina obliterated the coastal and inland portions of Mississippi. Study conducted in Southern Mississippi after Hurricane Karina by Gabe et al. 2005 showed additional dimension and highlights the extent and forms of damages inflicted on Mississippi's Gulf coast counties of Harrison, Hancock and Jackson in the month of August 28, 2005 during Hurricane Katrina.

\section{Data acquisition}

The spatial data for this study was obtained from the University of Maryland Institute for Advanced Computer Studies (UMIACS) imagery website (UMIACS 2014). This consists of two pair of Landsat Enhanced Thematic Mapper Plus (ETM+) WRS-2 satellite data acquired between November 18, 1999 and November 27, 1999 covering the six Southern Mississippi counties (Fig. 1). The path and row of the satellite data are 22 and 39; and 21

Table 1 Population of the Mississippi MSA - 1990-2010 (Wikipedia 2013)

\begin{tabular}{llllcr}
\hline Metropolitan Statistical Area (MSA) & 1990 & 2000 & 2010 & Growth rate (1990-2000) \% & Growth rate (2000-2010) \% \\
\hline Jackson MSA & 446,941 & 497,197 & 539,057 & 11.24 & 8.42 \\
Gulfport - Biloxi MSA & 207,875 & 246,190 & 248,820 & 18.43 & 1.07 \\
Memphis, TN-AR-MS MSA ${ }^{\text {a }}$ & 127,867 & 176,789 & 238,060 & 38.26 & 34.66 \\
Pascagoula MSA & 131,916 & 150,564 & 162,246 & 14.14 & 7.76 \\
Hattiesburg MSA & 109,603 & 123,812 & 142,842 & 12.96 & 15.37 \\
\hline
\end{tabular}

apopulation figures only reflect the Mississippi portion of the four counties (Tunica, Desoto, Tate and Marshall) of the Memphis, TN-AR-MS metro area 
and 39 respectively. Elevation data was obtained from the Mississippi Automated Resource Information System (MARIS) data clearing website, and also from the National Elevation Dataset (NED) produced by the United States Geological Survey (USGS) seamless data warehouse (MARIS 2014; USGS 2015).

\section{Data processing}

\section{Satellite data}

Landsat ETM+ images were processed using ERDAS IMAGINE 2010 image processing software (Erdas 2010). The images imported into ERDAS as single band and were housed into ERDAS using ERDAS native file format GEOTIFF. Bands 1-6 were grouped together by employing ERDAS Layer Stack modules. This was followed by radiometric correction of all the images for variation in sun angle and atmospheric effects.

Additionally, all the images were geometrically corrected to remove, haze, scan lines and speckles; and referenced to the Mississippi ground based coordinate system and Datum. From there, Landsat ETM+ data of November 18, 1999 and November 27, 1999 were mosaicked. This was followed by a histogram equalization enhancement technique performed on all the images. Later, the counties (Hancock, Harrison, Jackson, George, Stone and Pearl River) Shape file was imported into ERDAS, and used as ERDAS Area of Interest Tool (AOI) file to subset the ETM+ image of the study area.

\section{Elevation data}

All the six elevation data for each county were mosaicked using ERDAS Mosaic Pro. The process is shown in Fig. 5 where all the individual NED elevation data covering each county were imported into ERDAS Mosaic Pro to create a single mosaic image of the study area. After mosaicking the elevation data, the image was imported into Global Mapper evaluation software to create the Digital Elevation Model (DEM) surface of the entire study area shown in Fig. 1.

\section{Image to image registration}

Since the elevation and satellite data are in different projection, both images were co-registered using the satellite data as a base. This procedure permits overlay of both images. After co-registering the images, the mosaicked elevation data covering the study were used as template to subset the Landsat ETM+ data of the study area.

\section{Image drape}

Image Drape was performed using ERDAS IMAGINE Virtual GIS. The output image was then draped over the NED elevation data for visualization purposes with vertical exaggeration of $5 \mathrm{~m}$.

\section{Results and discussion}

The colorful imageries as represented in Fig. 3 shows three coastal counties and Figs. 4 and 5 shows the gridded image of digital elevation model of the six counties

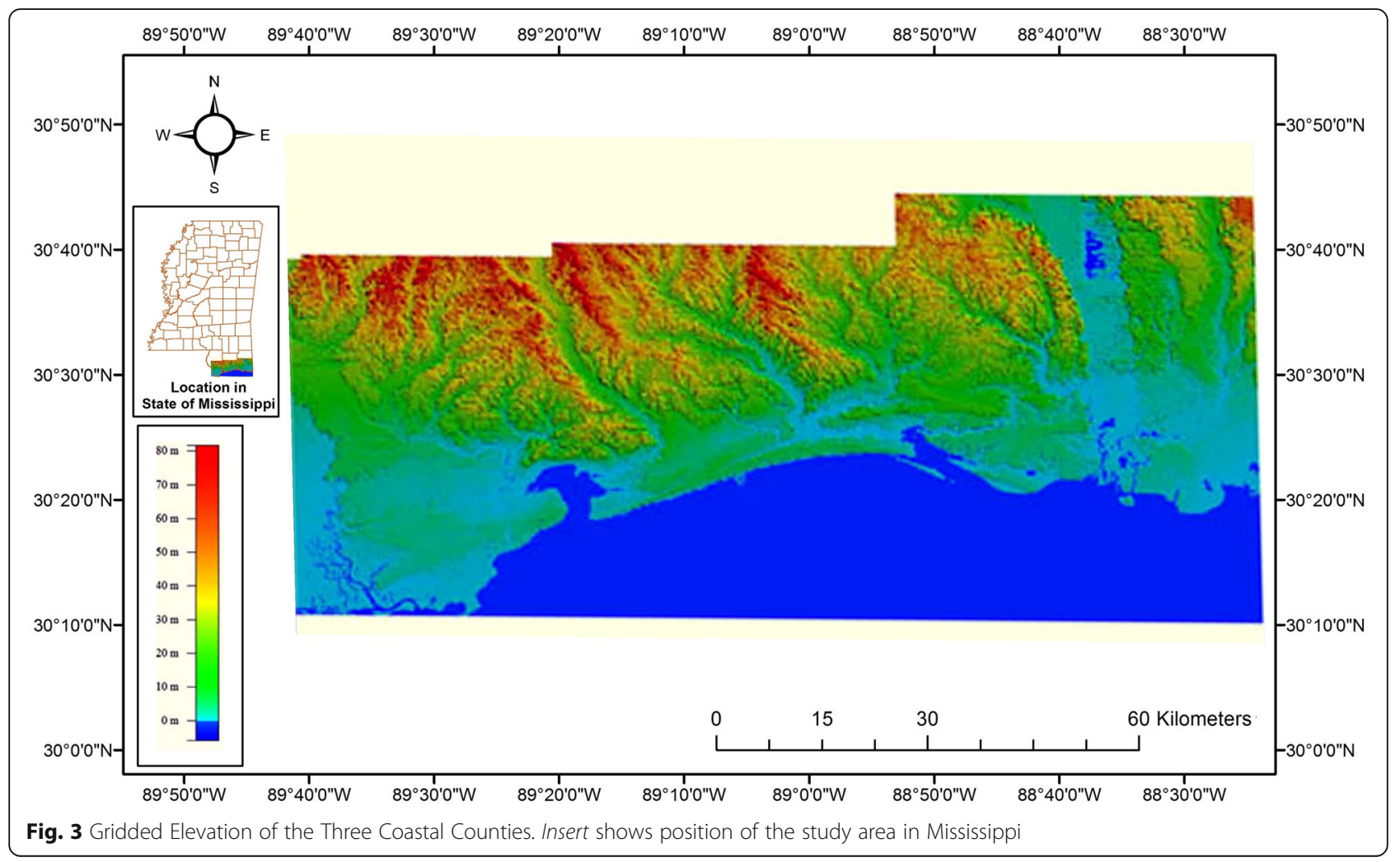




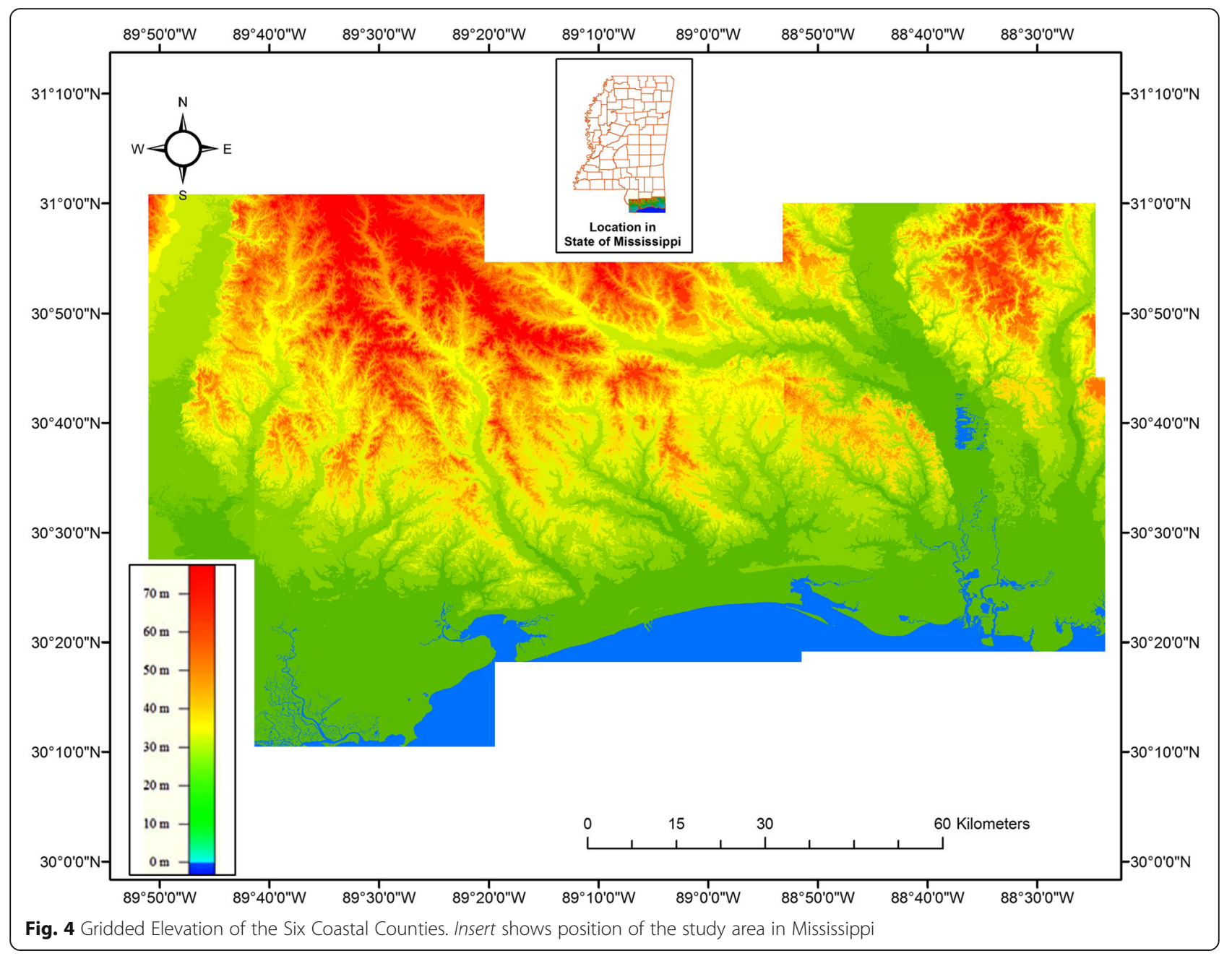

in the study area. While Fig. 6 offers a telegenic display of the draped image, Figs. 3, 4, 5 and 6 highlight the physical attributes captured in the form of topography and slope of the study area. Further along as shown in these figures, the area beside the coast appears wide with a fairly uniform and gentle slope, while steeper areas are found in the northern part of the study area.

Based on the geo-spatial analysis as shown so far, several interesting points did emerge clearly and directly. In the first place the topographic surface map of the study area (Figs. 3, 4 and 5), reveals that the study area stretches through a very vulnerable spot. This was evident with the heavy precipitations that inundated the area especially during Hurricane Katrina debacle in 2005 and most recently storm by Isaac (that are consistent with characteristics of a tropical storm). In being at the receiving end of potentially large flood waters from oceans and the surrounding high elevations, the study area is at epicenter of most coastal disasters. This vulnerability is also evident in Fig. 6 which shows the draped map of the area. Under such a scenario, the flat coastal plain imageries
(Figs. 3, 4 and 5) not only increases the probability of flood hazards, but are exacerbated by acceleration of water flows across such impervious surfaces.

Considering that all modern urban development is characterized by the use of concrete and asphalt, neither one of which promotes water infiltration. The urban context and form adjacent to the study area then inherently accentuates heavy flood risks.

\section{Policy Significance}

These data can enhance decision-making as a support tool in coastal zone management by pinpointing the exact locations of vulnerable areas in the communities at risk. For example, environmental managers need regular access to simulations of complex spatial data in a simplified way to optimize quick assessment of where the damage is going concentrated during flooding disasters and inclement weather debacles. Access to such a tool can improve the capability of planners in the formulation of effective evacuation plans to help emergency service workers and first responders direct the 


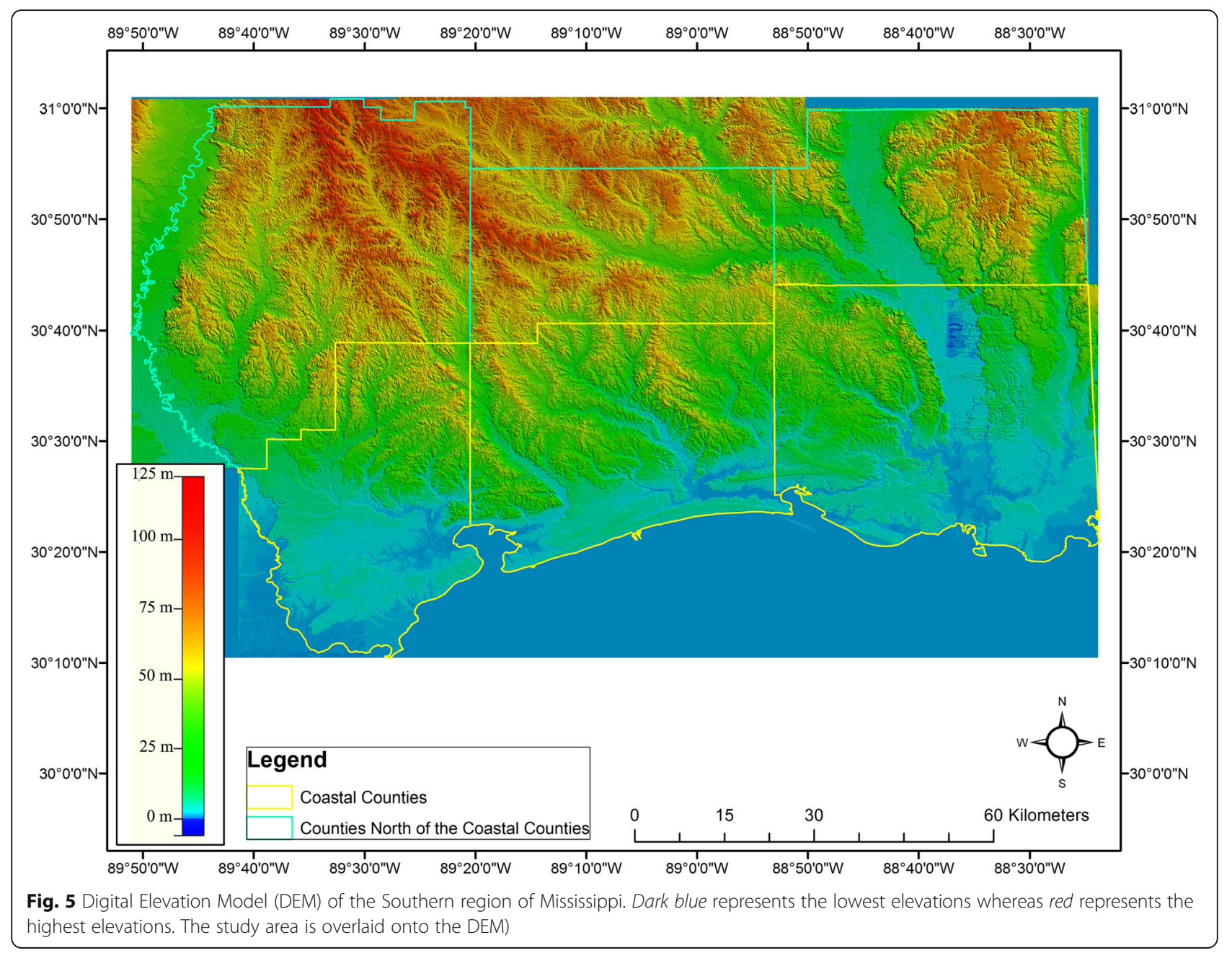

population at risk in the most efficient manner to safer grounds during crisis. It is also helpful in defining the locations and elevations where levies could be installed to protect the area from flood damage. The results from the data (Figs. 3, 4 and 5) and 3D visualization from the image drape (Fig. 6) has the potential to facilitate better understanding of the landscape such as geomorphological processes as well as trends and slope of the coastal area. This can also help planners anticipate future challenges by attending to and correcting spatial planning problems that would help minimize residents' vulnerability to natural and man-made disasters along the coast. As well, the output of the DEM (Figs. 3, 4 and 5) forms an important tool in our understanding of how these changes and future storms will affect possible impending flood waters when biophysical forces interact with social environments in coastal areas.

In terms of mitigations, policy options focused on dealing with a flooding or other coastal-zone environmental crisis are needed. On the other hand, the government could relocate much of the population, or build drainage ditches on the flat plains identified in this study to accommodate flood flows. This could completely or partially minimize the damaging impact of any flooding. However, any options that involve population relocation may require consent from individuals and groups affected; otherwise the relocation program may fail.

Finally, the results of GIS and remote sensing imagery analysis with focus on the coastal zone herein, could serve as a powerful instructional and sensitizing tool for the population at large, which may not appreciate the dangers experienced in the coastal areas of Southern Mississippi as a result of overpopulation. To enhance and expand the spheres of influence of these educational materials, the imagery and other visual documents like the surfaces generated in this study could be published in local newspapers.

\section{Conclusions}

In the context of the objectives of the research anchored on the applications of GIS and remote sensing towards efficient land administration and coastal resource 


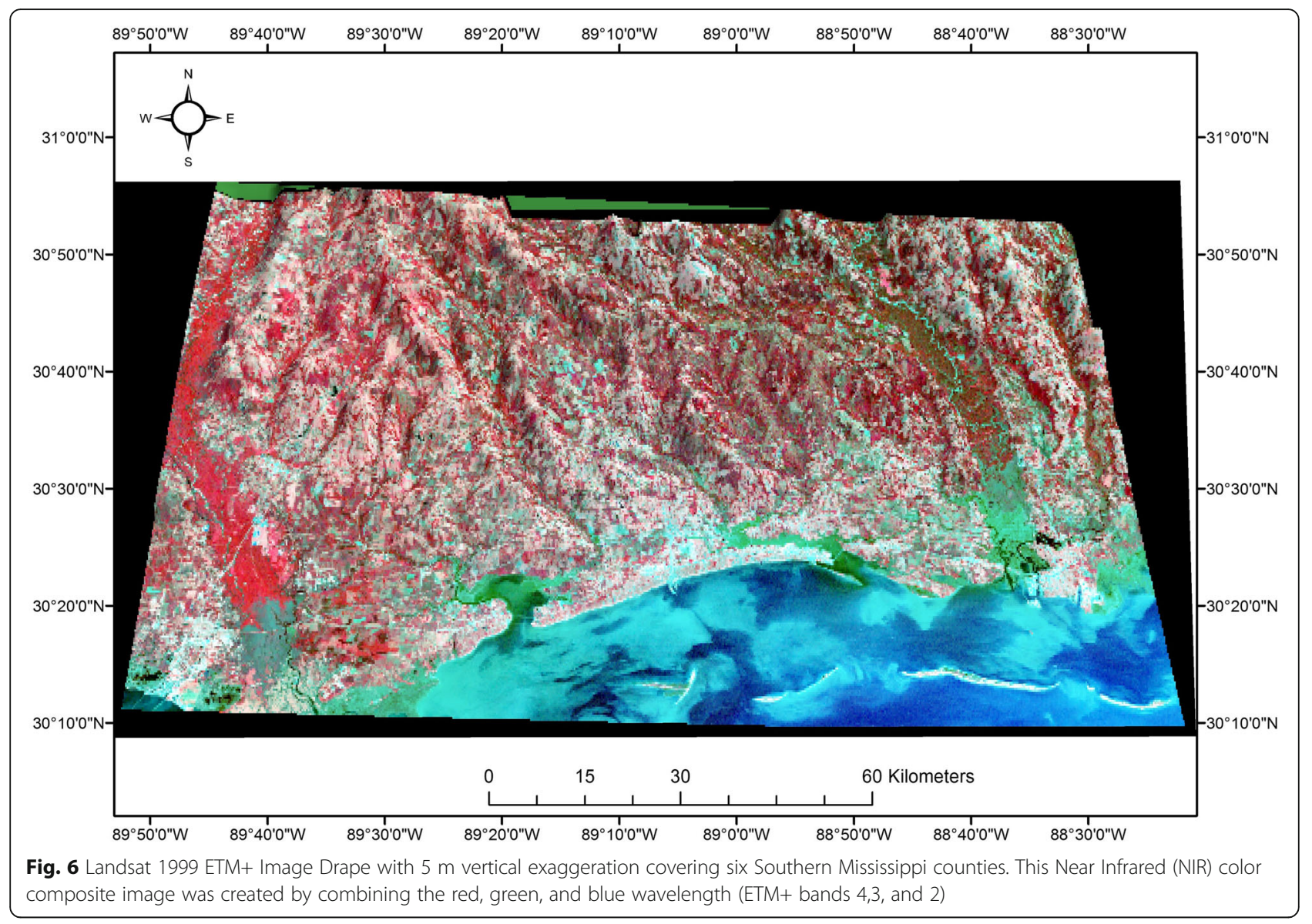

management in six coastal counties in an ecologically fragile area already dubbed the epicenter of coastal disasters. Considering the changes that took place in the six counties after Hurricane Katrina debacle, the findings in this study not only stand out, but they remain highly beneficial to decision makers made up of planners and policy makers in several ways. Just as the study injected elements of novelty by identifying digital elevation model information and the draping of the satellite data for the six counties in low lying areas, revealing the steeper areas in the north portion of the study stands out as a major finding and study contribution in a way beneficial to decision makers in the region. With that they are now better informed in sharing and cautioning and pinpointing to the public the hidden critical pathways to coastal vulnerability that were previously unknown to ordinary people. At a time when the state authorities are grappling with how to respond to recurrent coastal disasters ranging from river cresting and tropical storms known for their costly impacts. The precision of integrated GIS and remote sensing techniques in delineating the slope and paths of costal hazards in low lying and steep zones of the study area of south Mississippi stands as embodiment of technical proficiency with the latest advances in geospatial analysis.

The policy significance is that without such an indepth analysis and compilation of the stressors as shown in the study, natural resource managers in the region would not have known the extent to which death traps like steep areas in coastal areas exacerbate risk exposures in low lying areas to the detriment of communities. This creates the basis for serious intervention measures between counties, environmental regulators and communities who are endlessly at the receiving end of coastal hazards. In so doing, the research added an environmental safeguard dimension which is critical in detecting hazards and ensuring the welfare of communities and the preservation of a delicate ecosystem already overstretched by stressors. Showing these warning signals in the face of mounting stressors like storms, tropical hurricanes and others remains a step in the right direction. Making citizens aware of these actualities gives them the opportunity to track areas at risk within their vicinity and the need to target such places for mitigation due to the dangers to their wellbeing. In showing the vulnerability of the study area to coastal zone hazards, 
the study reiterated that GIS and remote sensing analysis of coastal hazards as decision support tool for mangers are vital to the ecosystem protection and welfare of communities in the Southern Mississippi region.

\section{Acknowledgements}

The authors would like to thank International Consortium on Geo-disaster Reduction (ICGdR) for proving funds to cover the cost of the Article Processing Charges (APCS).

\section{Authors' contributions}

YAT, ECM and TAS searched the satellite, elevation data and performed literature review. YAT also performed image processing and analysis. All authors read and approved the final manuscript.

\section{Competing interests}

The authors declare that they have no competing interests.

\section{Author details}

${ }^{1}$ Department of Urban and Regional Planning, Jackson State University, Jackson, MS 39211, USA. ${ }^{2}$ USDA Subtropical Horticulture Research Station, Miami, FL 33158, USA.

Received: 1 September 2016 Accepted: 12 November 2016 Published online: 01 December 2016

\section{References}

ERDAS. 2010. ERDAS field guide. Norcross: ERDAS.

Frihy, O.E. 2001. The necessity of environmental impact assessment (EIA) in implementing coastal projects: lessons learned from the Egyptian Mediterranean coast. Ocean and Coastal Management 44: 489-516.

Gabe, T., G. Falk, M. McCarty, and V.W. Mason. 2005. Hurricane Katrina: socialdemographic characteristics of impacted areas. Congressional Research Service (CRS) Report for Congress. The Library of Congress. http://www.tidec. org/sites/default/files/uploads/crsrept.pdf. Accessed 14 May 2015

Gillis, J.R. 2014. Why sand is disappearing. The New York Times, http://www. nytimes.com/2014/11/05/opinion/why-sand-is-disappearing.html?_r=0. Accessed 20 Apr 2015.

Merem, E.C. 2012. The applications of geo-info systems to gauge the susceptibility of coastal areas in Louisiana and Mississippi. The American Journal of Geographic Information Systems. (AGIS) 1(3): 46-65.

Merem, E.C. 2013. Geospatial assessment of the impacts of changing agricultural landscape in Louisiana. The Journal of Marine Sciences 3: 19-29.

Merem, E.C., J. Wesley, C. Richardson, D. Forster, C. Romano, and J. Williams. 2011. Using geospatial information systems in analyzing urbanization impacts on stream southern habitats in Mississippi coastal ecosystem. Journal of Environmental Science and Engineering 5(12): 1624-1641.

Merem, E.C., Y.A. Twumasi, C. Richardson, and D. Forster. 2012a. Using GIS and climate risk information systems to analyze the vulnerability of coastal counties in Louisiana and Mississippi. Resources and Environment 1(1): 1-18.

Merem, E.C., Y.A. Twumasi, and C. Richardson. 2012b. The use of geospatial information systems in the analysis of pollution trends in southern Mississippi region. American Journal of Environmental Science and Engineering 1(1): 14-29.

Mississippi Automated Resource Information System (MARIS). 2014. Free Mississippi state-wide public GIS data. http://www.maris.state.ms.us/. Accessed 14 May 2014

Nadaoka, K., 2005. Coastal ecosystems response to climate change and human impact in the Asia-Pacific Region (CERCCHI Project). Paper presented at the 5th Science Council of Asia (SCA) Conference (Bioscience and biotechnology for sustainable development: Future of Asian economy). May 11-13. Hanoi Daewoo Hotel, Hanoi, Vietnam. http://www.scj.go.jp/en/sca/activities/ conferences/conf_5_programs/pdf/5thas3nadaoka.pdf. Accessed 14 May 2015.

Osei, A., E.C. Merem, and Y.A. Twumasi. 2006. Use of remote sensing data to detect environmental degradation in the coastal region of Southern Nigeria. In Proceedings of the International Society for Photogrammetry and Remote Sensing (ISPRS) Mid-term Remote Sensing Symposium: From Pixels to Processes. Enschede, the Netherlands, 8-11 May 2006.

Oswell, A. 2015. Mangrove forests: threats. Washington DC: World Wide Fund for Nature (WWF). http://wwf.panda.org/about_our_earth/blue_planet/coasts/ mangroves/mangrove_threats/. Accessed 20 Apr 2015.
Pan, P.S.Y. 2005. Monitoring coastal environments using remote sensing and GIS. In G/S for coastal zone management, ed. D. Bartlett and J. Smith, 61-75. London: CRC.

Romine, B.M., and C.H. Fletcher. 2013. A summary of historical shoreline changes on beaches of Kauai, Oahu, and Maui, Hawaii. Journal of Coastal Research 29(3): 605-614. http://dx.doi.org/10.2112/JCOASTRESD-11-00202.1.

Rubinoff, P., N.D. Vinhateiro, and C. Piecuch. 2008. Summary of coastal program initiatives that address sea level rise as a result of climate change, 1-50. Rhode Island Sea Grant/Coastal Resources Center, Rl: University of Rhode Island.

Shi, C., S.M. Hutchinson, L. Yu, and S. Xu. 2001. Towards a sustainable coast: an integrated coastal zone management framework for Shanghai, People's Republic of China. Ocean and Coastal Management 44: 411-427.

Snoussi, M., and E.H.T. Aoul. 2000. Integrated coastal zone management programme northwest African region case. Ocean and Coastal Management 43: 1033-1045

Stanbury, K.B., and R.M. Starr. 1999. Applications of Geographic Information Systems (GIS) to habitat assessment and marine resource management. Oceonologica Acta 22(6): 699-703.

Tibbets, J.H. 2007. Rising tide. Will climate change drown coastal wetlands. Coastal Heritage 21(1): 2-14

Twumasi, Y.A.r T.L. Coleman, and A. Manu. 2003. Integrated resource databases for coastal zone management of Metropolitan Accra. In Proceedings of the Annual Convention and Exhibition of the American Society for the Photogrammetry and Remote Sensing (ACSM-ASPRS), Bethesda, Maryland (on CD ROM ISBN 1-57083-069-X), Anchorage, Alaska, 5-9 May 2003.

Twumasi, Y.A., T.L. Coleman, and A. Manu. 2006. Remote sensing and GIS applications in coastal zone management. Position/T 6(1): 18-23.

Twumasi, Y.A., A.B. Johnson, and E.C. Merem. 2011. Satellite Image fusion with DEM for 3D terrain visualization and coastal zone management: A case study of the Southern Mississippi. Paper presented at the 12th Annual Coastal Development Strategies Conference, organized by the Mississippi Department of Marine Resources and Mississippi Automated Resource Information System (MARIS). Biloxi: IP Casino Resort Spa. 11-12 May 2011.

United States Census Bureau. 2013. Metropolitan and Micropolitan. http://www. census.gov/population/www/metroareas/metrodef.html. Accessed 14 May 2015.

University of Maryland Institute for Advanced Computer Studies (UMIACS). 2014. Global Land Cover Facility (GLCF). http://glcf.umd.edu/data/. Accessed 15 Aug 2014.

USGS. 2015. The National Map. http://nationalmap.gov/viewer.html. Accessed 14 May 2015.

Van Heuvel, T. 1995. Shifting sands: coastline management with GIS in the Netherlands. GIS Europe 4(2): xiv-xvi.

Wikipedia. 2013. List of metropolitan areas in Mississippi. http://en.wikipedia.org/ wiki/List_of_metropolitan_areas_in_Mississippi. Accessed 14 May 2015.

Woodruff, J.D., J.L. Irish, and S.J. Camargo. 2013. Coastal flooding by tropical cyclones and sea-level rise. Nature 504: 44-52.

Yap, H.T. 2000. The case for restoration of tropical coastal ecosystems. Ocean and Coastal Management 43: 841-851.

\section{Submit your manuscript to a SpringerOpen ${ }^{\circ}$ journal and benefit from:}

- Convenient online submission

$\checkmark$ Rigorous peer review

- Immediate publication on acceptance

- Open access: articles freely available online

- High visibility within the field

- Retaining the copyright to your article

Submit your next manuscript at $\boldsymbol{\wedge}$ springeropen.com 